\title{
Chão em Chamas: Simbologias de um México em Busca de Redenção ${ }^{1}$
}

Tatiana Lotierzo

"Um conto sempre conta duas histórias", escreve Piglia (I994). "O conto se constrói para fazer aparecer artificialmente algo que estava oculto. Reproduz a busca sempre renovada de uma experiência única que nos permita ver, sob a superfície opaca da vida, uma verdade secreta". Chão em chamas é uma coletânea de I7 contos. Publicada originalmente em I953, a obra reflete a "obsessão pelo corte, pelo polimento final, pelo secar de um texto até reduzi-lo à mais rigorosa exatidão", que Eric Nepomuceno² (2004) atribui ao autor. "Ele alterou os textos, retocou palavras, chegou a alterar a ordem dos contos, expurgou do livro de contos pelo menos um relato - Passo do norte - durante anos" (idem. ib.). O dia do desmoronamento e A herança de Matilde Ancángel foram acrescentados na década de I970. Na década de I980, Macário foi trasladado do início para o meio da obra, entre Talpa e Chão em chamas. Nessa ordem, a obra compõe um movimento da ex-

I Texto produzido para a disciplina História da América Independente II, ministrada pelo prof. Júlio Pimentel Pinto, no departamento de história da FFLCH-USP.

2 Em Anotações sobre um gigante silencioso, o prefácio à edição brasileira. In: Pedro Páramo \& Chão em Chamas. Rio de Janeiro, Record, 2004. 
pectativa à desilusão, aludindo a uma característica identificada por Octavio Paz na cultura mexicana: a relação com a festa.

Segundo Octavio Paz (I976), "o mexicano não se diverte: quer se ultrapassar, pular o muro da solidão que durante o resto do ano o torna incomunicável”, escreve. Nos dias de festa,

o silencioso mexicano assobia, grita, canta, solta foguetes, descarrega a pistola no ar. Descarrega a alma. E seu grito, como os fogos de que tanto gostamos, sobe ao céu, estoura numa explosão verde, vermelha, azul e branca e cai vertiginoso, deixando uma calda de chispas douradas. Nessa noite, os amigos que durante meses não pronunciaram outras palavras senão as ordenadas pela cortesia indispensável embebedam-se juntos, fazem-se confidências, choram as mesmas dores, descobrem-se irmãos e, às vezes, para o demonstrar, matam-se entre si (op. cit.).

Embora possa surpreender ou chocar, a celebração da morte é perfeitamente factível nesse contexto. "O mexicano (...) freqüenta-a, ri dela, a acaricia, dorme com ela, festeja-a - é um de seus brinquedos favoritos e seu amor mais permanente" (op. cit.). Chão em chamas é assim uma composição em que festa e morte se misturam, criando uma atmosfera assombrosa - ou maravilhosa, para lembrar Alejo Carpentier ${ }^{3}$ (I987) - em torno das personagens, cenários e até do próprio leitor, convidado a adentrar nesse mundo e compartilhá-lo pelos narradores. Dessa forma, é possível entender nos contos de Rulfo uma leitura da Revolução Mexicana, misto de festa e morte: "A revolução é uma busca de nós mesmos e um regresso à mãe. E, por isso, é também uma festa, (...) um excesso e um gasto, um chegar aos extremos, um estouro de alegria e desamparo, um grito de orfandade e de júbilo, de suicídio e de vida, tudo misturado”, considera Paz (op. cit.).

\section{Fogo, Água e Vapor}

Seguindo o fio da teoria proposta por Piglia, adentramos em Chão em chamas como quem afunda num pântano lamacento. A escolha pelo conto privilegia o

3 "Tudo o que é insólito, tudo o que é assombroso, tudo o que escapa às normas estabelecidas é maravilhoso".

4 "O real maravilhoso, que eu defendo, e que é o nosso real maravilhoso, é aquele que encontramos em estado bruto, latente, onipresente em tudo o que é latino-americano. Aqui o insólito é cotidiano, sempre foi cotidiano”. 
mistério, o indizível, escancarado por olhos plasmados que fitam a morte - namorando-a, talvez, completamente entregues, apaixonados. A obra é coberta por uma neblina de "real maravilhoso" 4 (CARPEntier, op. cit.) que paira sobre acontecimentos, personagens e simbologias que assomam ao mesmo tempo, descontínuas e presentificadas, à caráter ou fantasiadas, como numa festa.

Tal infixidez se reflete ora de modo taciturno, ora explosivo; ora gélido, ora em chamas. Fogo e água compõem uma oposição que atravessa a obra e a unifica. O movimento de águas enfurecidas contra a terra que arde em labaredas, queima e se consome forma o corpo de um conjunto de metáforas. Podemos inferir daí que a grande personagem de Chão em chamas é a terra, castigada pelo fogo da disputa entre os homens; e que a revolução brota das entranhas da mesma terra, dos céus, naturalizada e indomável como torrentes em revolta, chuvas e geadas impiedosas. Em torno da terra, encadeia-se um infindável conjunto de reações, perdendo-se a compreensão de passado, futuro e presente.

Em E nos deram a terra, tudo começa com "uma gota d'água, grande, gorda, fazendo um furo na terra e deixando uma placa como se fosse uma cusparada": o governo mexicano distribui aos camponeses as terras inférteis de um chapadão fervendo sob o sol. O fogo se alastra em Chão em chamas. O milharal é incendiado à época da colheita. O chapadão é "transformado em pura brasa" e consome também os canaviais, a fumaça "cheirando a garapa e mel”. A água está no "tumulto de vozes amontoadas, fazendo um ruído igual ao da água crescida quando roda sobre pedregais"; e no rio, imagem recorrente na obra: "a matança foi grande. Na hora não percebi porque afundei no rio debaixo do meu cavalo morto, e a corrente nos arrastou até longe, até um remanso baixinho de água e cheio de areia".

Os vapores também jogam um papel fundamental nessa composição: fogo e água aniquilam-se a si mesmos. Por vezes, a poeira levantada pelo movimento de multidões em marcha ou grupos em peregrinação cria a ilusão de fumaça: as pessoas formam um rio sobre a terra quente, sob o sol escaldante, o suor escorrendo de seus rostos e corpos. As velhas de Anacleto Morones vêm levantando poeira, "vestidas de negro, suando como mulas, no meio do raio de sol". Chegam "jorrando suor e com os cabelos untados na cara como se tivesse chovido nelas". O caminho de Talpa era "largo parecido com a corrente de um rio, que nos fazia andar arrastados" e "da terra se erguia, com o bulir das pessoas, uma poeira branca feito farinha de milho que subia muito alto e tornava a cair" em movimento contínuo.

O fogo, que a tudo devora, ganha dimensões vertiginosas na obra, como já anuncia o título. Em português, mantendo-se a intenção do espanhol, Chão em chamas é aliteração e assonância e reverbera o som do fogo crispando; visu- 
almente, as palavras compõem a imagem das labaredas. Chão em chamas expressa um fascínio pela destruição: "Das tulhas da fazenda erguia-se mais alta a chamarada, como se um charco de aguarrás estivesse queimando. As chispas voavam e formavam uma grande rosca na escuridão do céu, formando grandes nuvens alumbradas". Há o fogo natural ou naturalizado (o calor aniquilador do sol); o fogo das luzes (como as lâmpadas onde morrem os bichos-de-luz, em Luvina, alusão às idéias liberais); o fogo ateado e atiçado pelos homens; e o fogo associado às mulheres.

Identificadas com o calor, as chamas, o ardor, o pecado, a perdição, o inferno, as figuras femininas têm o poder de amalgamar significados, misturando-os. Através das mulheres, faz-se referência à pátria que acalenta e abandona seu filho (o Estado e, por extensão, o povo). Ou à Igreja que explora seus fiéis. Em Luvina, a associação entre pátria e mulher é declarada: segundo o narrador, para os habitantes de Luvina, o Governo não tem mãe. "Esse senhor chamado Governo só se lembra deles quando algum de seus rapazes fez uma safadeza aqui embaixo. Então manda alguém atrás dele, até Luvina, e o matam”.

A mulher corrompida também pode ser lida como pátria em transformação. Em É que somos muito pobres, Tacha perde a única coisa que, aos olhos do irmão-narrador, lhe atribuía valor: a vaca, ou seja, a propriedade. O animal é tudo o que seu pai lhe deu. Sem ele, a menina está fadada à perdição. Mais que isso, a vaca, chamada simbolicamente de Serpentina (brinquedo das festas públicas), é arrastada pelo rio que transborda (referência à multidão em revolta); para o irmão, as irmãs de Tacha também se corromperam ao voltar do rio. A mãe, simbolizando a pátria mexicana anterior à Revolução, "vira todas as suas lembranças pelo avesso e não consegue enxergar qual foi o seu mal ou seu pecado para que nascesse uma filha atrás da outra e todas com o mesmo costume ruim”. A transformação irrompe na menina em idade de virar mulher - prenúncio do surgimento de uma nova pátria mexicana. Cria-se uma imagem de extrema beleza para o caráter irreversível da transformação em curso: "Pela sua cara correm fiozinhos de água suja como se o rio tivesse entrado dentro dela".

Se Tacha tem o rio em si, em Talpa, Natália é quente como o fogo. O corpo de Tanilo, seu marido, é recoberto de bolhas, "como envenenado, cheio por dentro de água podre que saía por cada rachadura de suas pernas ou de seus braços". A metáfora do fogo, do calor, remete às Luzes que, perto demais, queimam. A morte de Tanilo, que tampouco a virgem de Talpa consegue salvar, sugere que a resposta às mazelas sociais não está nem no Estado burguês (laico), nem no passado colonial (cristão), embora ambos estejam bastante presentes no imaginário mexicano.

É possível inferir que, na obra, o fogo se refere à individualidade, enquanto as águas simbolizam coletividades, fazendo vez ao conflito entre indivíduo 
(o mexicano solitário) e nação. A oposição parece representar a dificuldade de construção de uma identidade ou projeto nacional. O Gristianismo, fundante da ética e dos valores desde a colonização, é rechaçado pelos liberais, mas o Liberalismo não dá lugar à fé e reproduz as desigualdades sociais. O vazio de projetos, o olhar perplexo para o nada empurram o mexicano extasiado à transgressão. Lança-se à morte com a convicção de uma vida melhor no reino dos céus. Lança-se à revolução com a convicção de uma vida melhor na terra.

O corpo de Tanilo Santos representa a contradição individual/coletivo. Recoberto de bolhas que remetem a queimaduras, verte água suja de dentro para fora. Natália e seu amante, que o conduzem à morte, remoem a memória do "crime". Eles não terminam juntos, pois o peso do passado interfere no presente - os fins não justificam os meios. $\mathrm{O}$ antigo México foi enterrado, mas não esquecido. "Talvez o corpo de Tanilo esteja muito perto de nós dois, estendido dentro da esteira enrolada; cheio por dentro e por fora do fervedouro de moscas azuis que zuniam como se fosse um grande ronco que saía de sua boca”, reflete o narrador.

\section{Os cães no caminho}

Um dito popular abre o capítulo Chão em chamas: "Já mataram a cachorra, mas ficaram os cachorrinhos...". A Cachorra é, inclusive, o nome de um dos personagens, guerrilheiro do exército de Pedro Zamora ${ }^{5}$ contra Petronilo Flores; o narrador do capítulo tem o apelido de "O filhote", assim como seu filho. A violência da guerra afasta os combatentes dos ideais de justiça e os leva a um pragmatismo em que se perde a visão do caminho a seguir. A metáfora dos cães - os companheiros do homem, a solidariedade - é tanto a fé no futuro, quanto sua incerteza: "O filhote" diz que o filho "era igualzinho a mim e com uma ponta de maldade no olhar". Mas curva a cabeça (gesto ambígüo) ao ouvir da mãe: "ele não é nenhum bandido e nem assassino. É boa gente". O conto marca a transição entre expectativa e desilusão, na obra, sintetizando em si o sentido da coletânea. A partir dele, passa-se a uma reflexão em profundidade sobre o impacto e os legados da Revolução.

A relação entre pai (passado) e filho (futuro) também dá o mote de Você não escuta os cães latirem, em que o velho carrega o filho doente nas costas por um caminho obscuro, na esperança de curá-lo. Este não ouve os cães, sugerindo os filhos do México revolucionário que não têm mais esperanças quanto ao país.

5 Zamora toma o nome emprestado de um personagem real, bandolero que "asolaba, robaba, plagiaba, quemaba haciendas y pueblos, violaba mujeres y mataba sín compasión” (CÁRdenAS, I987). 
Passo do norte mostra um filho a caminho dos Estados Unidos, que trava um diálogo carregado de ironia e amargura com o pai; Diga que não me matem! e A herança de Matilde Arcángel também abordam o tema.

O caminho a percorrer sofre mudanças no decorrer do livro. Na primeira parte, por exemplo, A colina das comadres mostra os Torricos olhando Zapotlán e pensando no caminho até lá. O narrador, que "não estava feito para andar em andanças" é ameaçado por Remigio e lhe enterra a agulha de costurar arreios (indicação de rumo), iluminada pela lua, pertinho do umbigo (individualidade): "comecei a ter muita fé", diz. A fé na Revolução é celebrada, comparada à festa: "Zapotlán estava soltando foguetes, enquanto que pelos lados onde joguei Remigio erguia-se uma grande revoada de urubus a cada troar dos foguetes” ${ }^{6}$. Em contraposição, A herança de Matilde Arcángel mostra a desilusão com o caminho seguido. Matilde, que tinha os caminhos mais longos que todos os caminhos que o arrieiro tinha andado na vida, está morta. Foi atropelada por um cavalo rosilho (vermelho e branco, fogoso e gélido - rosa) desembestado - metáfora para o progresso atarantado, indomável ${ }^{7}$. Escolheu um homem grande (poderoso) ao invés do arrieiro (conhecedor dos caminhos a seguir) e deixou como herança um homem pequeno.

\section{A Morte no Reflexo do Olhar}

Matilde Arcángel tinha um "olhar de semi-sonho que cavoucava, pregando-se dentro da gente como um prego que dá muito trabalho despregar"; Remigio Torrico era caolho, mas enxergava como ninguém, pois "o olho negro e meio fechado que sobrava parecia aproximar tanto as coisas que quase as trazia para suas mãos"; Tanilo venda seus olhos durante a penitência, os mesmo que na viagem estavam "muito abertos, como se olhasse a própria morte"; Felipa tem olhos claros, verdes como rãs, a madrinha, escuros como sapos; O filhote criança tinha olhos assustados, com uma ponta de maldade; $O$ homem carrega um peso que "haverá de ser visto por qualquer olho".

A repetição da referência ao olhar nos contos marca a presença da morte em cena, subvertendo tempo e espaço da narrativa. A morte está viva, ou, como diria Octavio Paz (I976), "nossa morte ilumina nossa vida". É importante tecer

6 A gente da Colina das Comadres "atravessava o mata-burro onde está o mastro das festas e desaparecia entre as azinheiras e não tornava a aparecer nunca jamais”, diz o narrador, em outra passagem.

7 Em Passo do Norte, Tránsito foge com um arrieiro, remetendo também à ilusão de desenvolvimento. 
considerações sobre esta figura à espreita em Chão em chamas. Em primeiro lugar, durante a leitura, não sabemos ao certo se as personagens estão vivas ou mortas. Os que já se foram, rememorados pelos narradores em primeira pessoa, com os quais o leitor tem a chance de dialogar, se fazem presentes. Além disso, a onipresença dos narradores os coloca como que viajantes do além-mundo, que deixaram seus relatos gravados em voice over (mais próximos da oralidade) para que fossem ouvidos por nós, leitores. Quando mencionam o tempo passado, o fazem sem situá-lo.

Os olhos por onde se chora, por vezes comparados a charcos d'água, fazem com que rios subterrâneos escorram por sobre a carne. Os rios e águas nos contos, em contraponto com a chama acesa do presente, podem ser lidos como representações da morte, na qual todos se igualam. Matilde morre com o rosto num charco d'água; em A colina das comadres, "a terra se fazia pegajosa assim que começava a chover, e depois havia um esparramo de pedras duras e afiadas feito facões" (a morte da terra); para o narrador, a vaca de Tacha só pode ter entrado no rio enquanto dormia; as velhas de Anacleto Morones tomam a água de goiaba, mas não do rio; o filho de Passo do norte diz ao pai que "Nos mataram (...) ao passar o rio" e, no entanto, volta para contar; Feliciano Ruelas sorve "um bocadinho de ar como se fosse mergulhar na água"; era bonito ver os soldados de Petronilo Flores "sem inimigo pela frente, como se mergulhassem na água funda e sem fundo"; O homem sabe que "o rio vira um nó e pode muito bem me devolver para um lugar para onde não quero regressar".

Luvina é a representação mais explícita do além-vida em Chão em chamas. O lugar, onde os arrieiros se recusam a entrar, é descrito com todas as características das cidades-fantasma. Curiosamente, a água é rara nesse paradeiro da morte: chove cerca de dez ou doze dias por ano. São "tormentas que açoitam a terra e a dilaceram", deixando "só o pedregal florindo em cima do morro" (talvez em referência a um túmulo). Espinhos d'água cravam nos pés e as nuvens dão apenas trovoadas. Outras referências à água são o mescal de hojasế, que faz dar cambalhotas como se alguém esporeasse quem bebe e as mulheres de Luvina "com seus cântaros ao ombro, com o xale balançando em suas cabeças e suas figuras negras sobre o negro fundo da noite (...) 'Vamos buscar água" , dizem.

O cenário em cinzas (resultado de chamas) e o fato de ali só morarem mulheres abandonadas, velhos e crianças que ainda não nasceram sugere a idéia de que "a vida é apenas uma metáfora com que a morte - ela também! - se quer enganar" (GOROSTIZA apud PAZ, op.cit.). Assim, Chão em chamas realiza uma grande

$8 \mathrm{O}$ mescal, bebida alcoólica com uma larva no interior, faz referência à morte. 
inversão: borrados os limites entre vida e morte e assumida a contraposição entre Luvina e os demais contos, pode-se pensar em Luvina como a vida e no restante do livro como a morte, reforçando-se a crítica social presente em toda a obra ${ }^{9}$. Ou ainda, Luvina pode ser um futuro que, inversamente à ordem lógica de qualquer investigação, deixa vestígios no passado. Sobre um passado conhecido e um presente em curso, estaria um futuro eterno, sem continuidade com o presente, ilusório. Luvina seria assim o resultado da política dos fins, que se perde nos meios. A festança descrita em $O$ dia do desmoronamento, em que o governador permanece "impávido" frente à matança e o caos, reflete a total ausência de um projeto político não-individualizado ou não-elitizado para o México.

Após pelo menos sete anos em revolução, o México permanece por décadas sob o governo de um mesmo partido. Apesar da Constituição de I9I7 ter incorporado um projeto de reforma agrária, não se levou em conta a questão da propriedade coletiva da terra. Os movimentos indígenas e campesinos de caráter reivindicatório resistem até hoje. As desigualdades sociais, somadas a acontecimentos recentes, como as acusações de fraude eleitoral e a guerra civil em Oaxaca, remontam à fragilidade dos projetos políticos, sociais e culturais frente à diversidade da "nação".

O chão permanece em chamas; talvez a revolução não tenha acabado; talvez siga intercalando momentos de letargia e euforia, em reprodução serial das indefinições e incertezas quanto ao futuro. A identidade mexicana flui como um rio caudaloso e estoura como fogos de artifício nas noites de céu límpido, rodopiando volátil entre a morte e a festa. A polissemia criada por Rulfo evoca fantasias assombrosas, êxtase e culpa de um povo em meio ao turbilhão, o revolver das entranhas da terra e o transbordar em fúria das águas em que navegam os mexicanos. Chão em chamas é um prisma do subdesenvolvimento: em certa medida barroco, entre moderno e antigo, arrastando as correntes de seus defuntos; amálgama de imagens da colonização, heróis, insígnias e brasões, num contexto em que fortuna e miséria gritam palavras de ordem de modo escandaloso ${ }^{10}$. Como a morte, a revolução reflete a vida de seu povo. E "ficaram os cachorrinhos...".

9 A morte também é sugerida pelos grilos, gafanhotos e cigarras nos contos. Em Macário, "Felipa diz que os grilos sempre fazem ruído, sem parar nem para respirar, para que todo mundo ouça os gritos das almas que estão penando no purgatório”. A referência está presente em A herança de Matilde Arcángel; Chão em chamas e Na madrugada, por exemplo.

IO "Sempre achamos que pudesse ser Hidalgo, ou Morelos, ou Venustiano Carranza", diz o narrador de $\mathrm{O}$ dia do desmoronamento, ao saber que a estátua da praça era de Benito Juárez. 


\section{Referências Bibliográficas}

Carpentier, Alejo. "O barroco e o real maravilhoso". In: A literatura do maravilhoso. São Paulo: Vértice, I987.

Munguia Gárdenas, Frederico. Antecedentesy datos biográficos de Juan Rulfo. Guadalajara: Unidad Editorial del Gobierno de Jalisco, I987.

Paz, Octavio. O labirinto da solidão. Rio de Janeiro: Paz e Terra, I976.

Piglia, Ricardo. O laboratório do escritor. Rio de Janeiro: Iluminuras, I994.

Rulfo, Juan. "Chão em chamas". In: Pedro Páramo \& Chão em Chamas. Rio de Janeiro: Record, 2004.

TATIANA Lotierzo é graduanda em história pela USP.

E-mail: tatianalotierzo@yahoo.com. 